\title{
Red cell distribution width and red cell distribution width to total serum calcium ratio as predictors of mortality in acute pancreatitis: a retrospective cohort study
}

\author{
Cihan Bedel ${ }^{1 \oplus,}$, Sefa Türkoğlu² ${ }^{2}$
}

${ }^{1}$ Department of Emergency Medicine, University of Health Sciences, Antalya Training and Research Hospital, Antalya, Turkey ${ }^{2}$ Department of Radiology, Denizli State Hospital, Denizli, Turkey

\begin{abstract}
Objectives: We investigated whether red cell distribution width (RDW) and red cell distribution width to total serum calcium (RDW-to-TSC) ratio were associated with mortality in patients with acute pancreatitis (AP).

Methods: A total of 170 patients who present emergency department between January 2017 and June 2018 with a diagnosis of AP were enrolled in this study. A comparison between survivor and nonsurvivor AP patients was performed. Diagnosis of AP were defined according to the revised Atlanta classification 2012. Variables evaluated included demographics, hospital stay, laboratorial parameters and mortality.

Results: AP related in-hospital mortality was $6.4 \%$. Red cell distribution (RDW), white blood cell (WBC), platelet, serum glucose and RDW-to-TSC ratio were associated with AP mortality. RDW-to-TSC ratio had the highest AUC $(0.88 ; 95 \%$ CI, 0.756-1.0), followed by RDW, serum glucose, platelet and WBC (AUC $=0.801$, $0.797,0.743$ and 0.687 respectively). A cut-off value of RDW-to-TSC ratio $>2.0$, the highest sensitivity $(91.9 \%)$, specificity $(81.1 \%)$, PPV $(82.9 \%)$, and NPV $(91.1 \%)$ were achieved for prediction of AP related in-hospital mortality in approximately $86.5 \%$ of the cases $(p<0.001)$.

Conclusions: RDW and TSC are simple, inexpensive routine serum parameters, provided in a complete blood count test and available at admission. This study showed that RDW $>16.6$ and RDW-to-TSC $>2.0$ were very good predictors for AP mortality.

Keywords: Acute pancreatitis, mortality, red cell distribution width, serum calcium
\end{abstract}

A cute pancreatitis (AP) is the sudden onset severe inflammation of pancreas and is one of the most frequent gastrointestinal causes of hospital admission [1]. The severity of the disease is varies from a mild, self-limiting form to a serious disease with severe local and systemic complications that may lead to multiorgan failure and death [2]. Several single and multiparameter predictors for assessing severity of the disease has been described [3, 4]. However, most of them are complex and cannot be applied early enough.

The Ranson score, the Bedside Index for Severity in Acute Pancreatitis score, the Acute Physiologic Assessment and Chronic Health Evaluation II score and the Glasgow-Imrie criteria are currently in wide use 
[4]. Whereas, simplified serum markers such as C-reactive protein (CRP), blood urea nitrogen (BUN) procalcitonin, interleukin-6, interleukin-8, , have been applied to estimate the prognosis or severity of the AP, but their results have been inconsistent and unrelated to the severity of the disease [5]. Until now, a single serum marker cannot predict the severity or mortality in AP during admission. Red cell distribution width (RDW) is a routine parameter of the complete blood count $(\mathrm{CBC})$ test, described as simple, easy, inexpensive and quantitative that measures size variability of erythrocytes [6]. RDW has been associated with inflammatory markers such as CRP and fibrinogen. Recent studies have shown that RDW is a strong and independent prognostic marker in many conditions such as cardiovascular diseases, pulmonary diseases and even cancer [7-9]. In addition to these conditions, RDW was also evaluated as a predictor of mortality in AP $[10,11]$.

RDW value and its association with other serum makers such as total serum calcium (TSC) has rarely been investigated as a potential biomarker of AP. Therefore, the aim of the study is to assess RDW and RDW-to-TSC ratio predictability for AP mortality.

\section{METHODS}

This retrospective study was approved by local ethical committee and all procedures were performed according to Helsinki declaration. A total of 170 patients who present emergency department (ED) between January 2017 and June 2018 with a diagnosis of AP were enrolled in this study. The diagnosis of AP requires 2 of the following 3 criteria : upper abdominal pain of acute onset; serum amylase or lipase elevation $\geq 3$ times the upper limit of normal; and characteristic findings of AP on contrast-enhanced computed tomography or abdominal ultrasonography [12]. We excluded patients with age $<18$ years, abdominal trauma, lack of enough data, chronic pancreatitis, malignancy, pregnant patients,, having additional diseases affecting hematologic system (including lymphoma, leukemia, and bone marrow malignancies), or other chronic inflammatory diseases (including tuberculosis, Henoch-Schönlein purpura) and any autoimmune disorders and patients with time from onset of disease to presentation in the ED greater than $24 \mathrm{~h}$. At the time of hospital admission, a thorough medical history and physical examination were taken. Blood samples were also collected for laboratory investigations within $1 \mathrm{~h}$ of admission and included: CBC including white blood cells (WBC), neutrophil count, lymphocyte count, PDW, platelets (PLT) and RDW, liver function tests, BUN, TSC, serum glucose (only for non-diabetic patients), lactate dehydrogenase (LDH) and additionally, RDW-to-TSC ratio and $\mathrm{RDW}$-to-platelets ratio were evaluated. The primary end point was in-hospital mortality.

\section{Statistical Analysis}

Statistical analysis was carried out using social package for social sciences version 18.0 for Windows (SPSS Inc., Chicago, IL, USA). Normality of data distribution was assessed with Kolmogorov-Smirnov or Shapiro-Wilk test. Continuous data were expressed as mean and standard deviation (SD) or median and interquartile range based on the normality of distribution. Groups were compared using Student's ttest or Mann-Whitney test. Categorical variables were expressed as frequency and percentage and compared using X2-test or Fisher's exact test. All significant factors on univariate analysis were considered for inclusion in multiple regression analysis to predict APrelated in-hospital mortality. The receiver operating characteristic (ROC) curves were plotted to measure and compare the performance of different parameters to determine mortality risk and to select the best cutoff point at which sensitivity, specificity, positive (PPV) and negative (NPV) predictive value, positive and negative likelihood ratio (+LR, $-\mathrm{LR})$ were calculated. All tests were two-tailed and statistical significance was assessed at $<0.05$.

\section{RESULTS}

\section{Characteristics of the Studied Patients}

A total of 170 patients with a diagnosed of AP was taken to the present study. There were 104 (61.2\%) male and $66(38.8 \%)$ female with a male to female ratio of 1.57:1. The median age was 58 years and their age ranged from 24 to 98 years with a mean of 57.68 \pm 16.2 . There were 11 patients $(6.4 \%)$ in the nonsurvivor group and 159 patients (93.6\%) in survivor group. The mean hospital stay was $8.3 \pm 9.2$ 
Table 1. Summary of the demographic and clinical characteristics of the patients

\begin{tabular}{|c|c|c|c|}
\hline Parameter & $\begin{array}{c}\text { Nonsurvivors } \\
(\mathrm{n}=11)\end{array}$ & $\begin{array}{c}\text { Survivors } \\
(\mathrm{n}=159)\end{array}$ & p value \\
\hline Age ( years) & $62.6 \pm 17.6$ & $57.3 \pm 16.1$ & 0.335 \\
\hline Gender (M/F), n (\%) & $6 / 5(54.5 / 45.5)$ & $98 / 61(61.6 / 38.4)$ & 0.752 \\
\hline WBC count $\left(10^{3} / \mathrm{mm}^{3}\right)$ & $15.2 \pm 5.5$ & $12.1 \pm 4.8$ & 0.038 \\
\hline Neutrophil count $\left(10^{3} / \mathrm{mm}^{3}\right)$ & $12.4 \pm 5.1$ & $9.5 \pm 5.1$ & 0.057 \\
\hline Lymphocyte count $\left(\times 10^{3} / \mathrm{mm}^{3}\right)$ & $1.4 \pm 0.6$ & $1.5 \pm 0.9$ & 0.559 \\
\hline Platelet count $\left(\times 10^{3} / \mathrm{mm}^{3}\right)$ & $331.7 \pm 100.5$ & $253.4 \pm 99.6$ & 0.007 \\
\hline RDW (\%) & $18.8 \pm 4.7$ & $14.8 \pm 1.8$ & 0.001 \\
\hline Serum amylase (U/L) & $212(46-1104)$ & $303.5(29-3982)$ & 0.323 \\
\hline Serum lipase (U/L & $496(121-3710)$ & $555(14-9692)$ & 0.713 \\
\hline AST (U/L) & $120(21-346)$ & $57(11-1768)$ & 0.175 \\
\hline ALT (U/L) & $46(15-120)$ & $45(16-1056)$ & 0.713 \\
\hline Total serum calcium $(\mathrm{mg} / \mathrm{dl})$ & $7.9 \pm 1.1$ & $8.7 \pm 0.8$ & 0.021 \\
\hline Serum glucose (mg/dl) & $238.8 \pm 91.1$ & $146.1 \pm 62.9$ & 0.001 \\
\hline Lactate dehydrogenase (U/L) & $312(155-427)$ & $270(121-2502)$ & 0.653 \\
\hline RDW-to-TSC ratio & $2.3 \pm 0.5$ & $1.7 \pm 0.3$ & $<0.001$ \\
\hline RDW-to-platelets ratio & $0.06 \pm 0.04$ & $0.23 \pm 1.96$ & 0.504 \\
\hline Hospitalisation day (days) & $14.7 \pm 10.4$ & $7.8 \pm 9.1$ & 0.019 \\
\hline
\end{tabular}

Data are shown as mean \pm standard deviation or median (range) or number $(\%)$. ALT $=$ alanine aminotransferase, $\mathrm{AST}=$ aspartate aminotransferase, $\mathrm{WBC}=$ white blood cell, RDW $=$ red cell distribution width, RDW-to-TSC ratio $=$ red cell distribution width to total serum calcium ratio

days. Demographic, clinical, and laboratory characteristics of survivors and non-survivors were summarized in Table 1. All the non-survivors where the levels of WBC, platelet, RDW, serum glucose and RDW-to-TSC ratio were significantly increased, while the levels of calcium was significantly decreased $(p<$ $0.05)$.
Risk Factors Analysis for AP Related In-Hospital Mortality

To define the factors which can predict AP related in-hospital mortality, multiple regression analysis was applied using the significant variables from the univariate analysis $(p<0.05)$ (Table 1). It was found that increased WBC, PLT, RDW, serum glucose and

Table 2. Multiple regression analysis of risk factors affected acute pancreatitis related inhospital mortality

\begin{tabular}{lcc}
\hline Variables & Odds ratio & $\boldsymbol{p}$ value \\
\hline WBC count $\left(\times 10^{3} / \mathrm{mm}^{3}\right)$ & $1.1(0.9-1.17)$ & 0.028 \\
Platelet count $\left(\times 10^{3} / \mathrm{mm}^{3}\right)$ & $1.2(0.8-1.69)$ & 0.012 \\
RDW $(\%)$ & $1.1(1-1.2)$ & 0.031 \\
Total serum calcium $(\mathrm{mg} / \mathrm{dl})$ & $0.9(0.7-1)$ & 0.447 \\
Serum glucose $(\mathrm{mg} / \mathrm{dl})$ & $1.2(0.9-1.4)$ & 0.001 \\
RDW-to-TSC ratio & $0.9(0.8-1.1)$ & $<0.001$ \\
\hline
\end{tabular}

$\mathrm{WBC}=$ white blood cell, $\mathrm{RDW}=$ red cell distribution width, $\mathrm{RDW}$-to-TSC ratio $=$ red cell distribution width to total serum calcium ratio 
Table 3. Diagnostic models for prediction of acute pancreatitis related in-hospital mortality

\begin{tabular}{|c|c|c|c|c|c|c|c|c|c|}
\hline & & B & SE & Wald & Sig. & $\begin{array}{l}\operatorname{Exp} \\
\text { (B) }\end{array}$ & \multicolumn{2}{|c|}{$\begin{array}{c}\text { 95\% CI } \\
\text { EXP (B) } \\
\text { Lower-Upper }\end{array}$} & \multirow{2}{*}{ 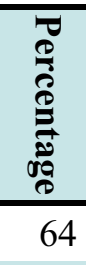 } \\
\hline & RDW & 0.044 & 0.007 & 6.068 & $<0.001$ & 0.424 & 0.030 & 0.059 & \\
\hline \multirow[t]{2}{*}{ Step 1} & Constant & 0.396 & 0.112 & 3.554 & $<0.001$ & & & & \\
\hline & RDW & 0.023 & 0.012 & 1.931 & 0.055 & 0.222 & -0.001 & 0.047 & \\
\hline \multirow[t]{2}{*}{ Step 2} & RDW-to-TSC & 0.161 & 0.073 & 2.200 & 0.029 & 0.253 & 0.017 & 0.305 & 82.2 \\
\hline & Constant & 0.432 & 0.111 & 3.875 & $<0.001$ & & 0.212 & 0.652 & \\
\hline
\end{tabular}

RDW $=$ red cell distribution width, RDW-to-TSC ratio $=$ red cell distribution width to total serum calcium ratio

RDW-to-TSC ratio were independent predictors of AP mortality $(p<0.05)$ (Table 2). Moreover, using multiple regression analysis with forward LR method to construct a model with higher accuracy for prediction of AP related in-hospital mortality, a combined use of RDW and RDW-to-TSC ratio offered an accuracy of $82.2 \%$ (Table 3 ).
Diagnostic Performance of Parameters for Prediction of AP Related In-Hospital Mortality

We investigated the effectiveness of WBC, PLT, RDW, serum glucose and RDW-to-TSC ratio in prediction of AP related in-hospital mortality using ROC analysis. It was found that the area under curve (AUC) values of these variables were statistically

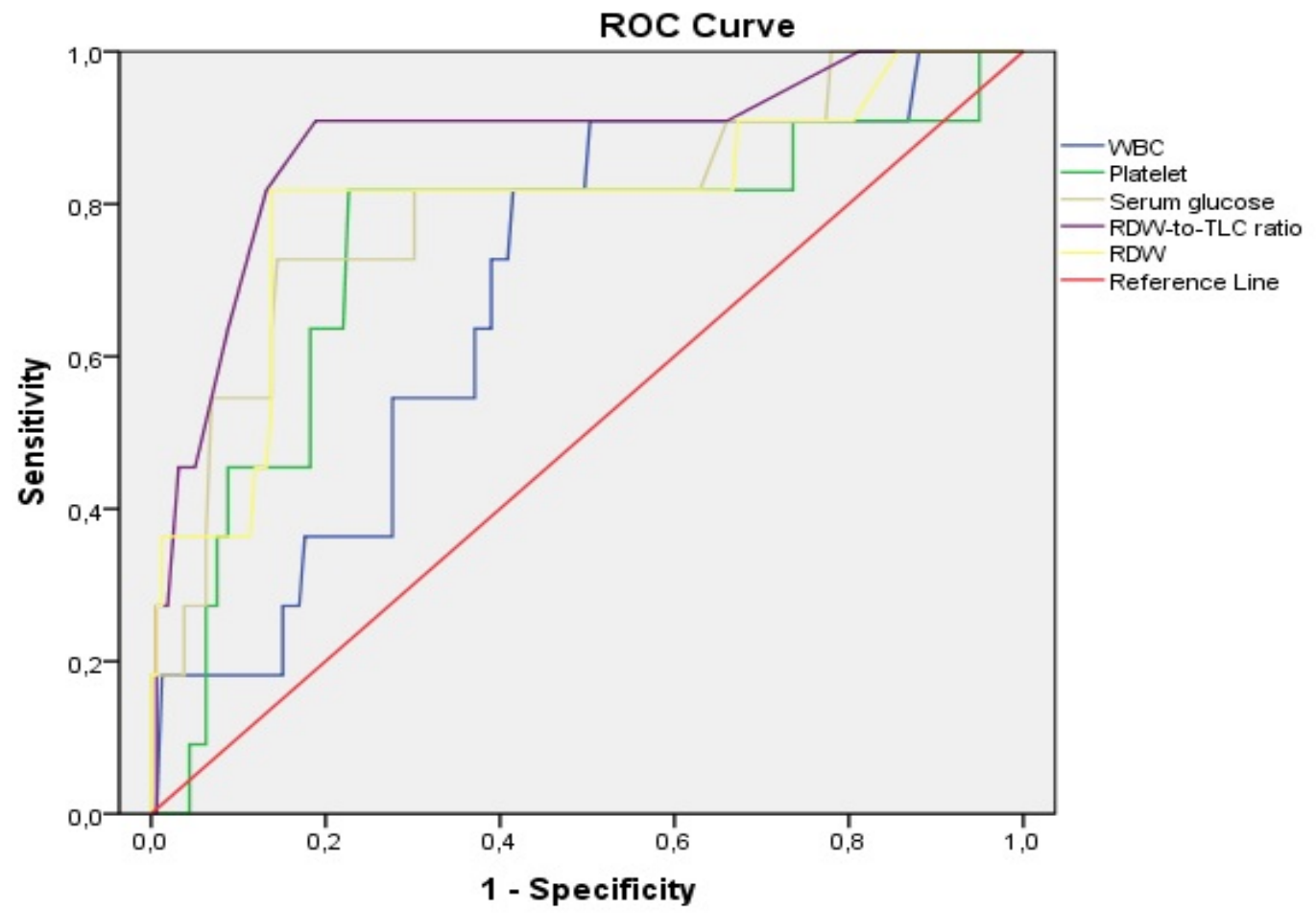

Fig. 1. Area under the receiver operating characteristic curve (AUC) of WBC, platelet, RDW, serum glucose and RDW-toTSC ratio to predict AP-related in-hospital mortality. RDW-to-TLC ratio had the highest AUC in predicting mortality (AUC

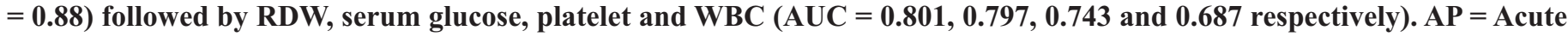
pancreatitis, $\mathrm{RDW}=$ Red cell distribution width, WBC $=$ white blood cell, $\mathrm{RDW}$-to-TSC $=$ Red cell distribution width-tototal serum calcium. 
Table 4. Diagnostic accuracy of prognostic parameters to predict acute pancreatitis related inhospital mortality with the best predictive cut-offs

\begin{tabular}{|c|c|c|c|c|c|c|c|c|c|}
\hline & $\begin{array}{c}\text { AUC } \\
95 \% \text { CI }\end{array}$ & $\begin{array}{l}\text { SEN } \\
(\%)\end{array}$ & $\begin{array}{l}\text { SPE } \\
(\%)\end{array}$ & $\begin{array}{l}\text { PPV } \\
(\%)\end{array}$ & $\begin{array}{l}\text { NPV } \\
(\%)\end{array}$ & $+\mathbf{L R}$ & $-\mathbf{L R}$ & $\begin{array}{c}\text { Accuracy } \\
(\%)\end{array}$ & $p$ value \\
\hline $\begin{array}{l}\text { WBC } \\
\left(>12.5 \times 10^{3}\right)\end{array}$ & $\begin{array}{c}0.687 \\
(0.541-0.833)\end{array}$ & 72.7 & 60.7 & 65.1 & 69.3 & 1.87 & 0.44 & 67 & 0.038 \\
\hline $\begin{array}{l}\text { Platelets } \\
\left(299.5 \times 10^{3}\right)\end{array}$ & $\begin{array}{c}0.743 \\
(0.569-0.917)\end{array}$ & 81.8 & 77.4 & 78.1 & 81.1 & 3.57 & 0.23 & 73.5 & 0.007 \\
\hline $\begin{array}{l}\text { RDW } \\
(>16.6 \%)\end{array}$ & $\begin{array}{c}0.801 \\
(0.640-0.963)\end{array}$ & 81.8 & 87.2 & 86.4 & 82.8 & 6.31 & 0.21 & 84.5 & 0.001 \\
\hline $\begin{array}{l}\text { Serum glucose } \\
(>151 \mathrm{mg} / \mathrm{dl})\end{array}$ & $\begin{array}{c}0.797 \\
(0.643-0.950)\end{array}$ & 83.6 & 70.7 & 74.3 & 81.6 & 2.9 & 0.23 & 77.5 & 0.001 \\
\hline $\begin{array}{l}\text { RDW-to-TSC ratio } \\
(>2.0)\end{array}$ & $\begin{array}{c}0.88 \\
(0.756-1)\end{array}$ & 91.9 & 81.1 & 82.9 & 91.1 & 4.84 & 0.1 & 86.5 & $<0.001$ \\
\hline
\end{tabular}

AUC $=$ area under the curve, $\mathrm{SEN}=$ sensitivity, $\mathrm{SPE}=$ specificity, $\mathrm{PPV}=$ positive predictive value, $\mathrm{NPV}=$ negative predictive value, $+\mathrm{LR}=$ positive likelihood ratio, $-\mathrm{LR}=$ negative likelihood ratio, $\mathrm{WBC}=$ white blood cell, $\mathrm{RDW}=$ red cell distribution width, RDW-to-TSC ratio = red cell distribution width to total serum calcium ratio

significant to predict AP mortality (Figure 1). RDWto-TSC ratio had the highest AUC $(0.88 ; 95 \% \mathrm{CI}$, 0.756-1.0), followed by RDW, serum glucose, platelet and $\mathrm{WBC}(\mathrm{AUC}=0.801,0.797,0.743$ and 0.687 respectively). Moreover, at a cut-off value of RDWto-TSC ratio $>2.0$, the highest sensitivity $(91.9 \%)$, specificity (81.1\%), PPV (82.9\%), and NPV (91.1\%) were achieved for prediction of AP related in-hospital mortalityin approximately $86.5 \%$ of the cases $(p<$ 0.001) (Table 4).

\section{DISCUSSION}

Recent studies have shown that RDW is a remarkable prognostic marker to determine the mortality risk in a wide range of clinical manifestations such as elderly patients with or without age-related diseases intensive care unit patients, cardiovascular diseases, and even those with acute dyspnea and pneumonia [13-15]. RDW has been recognized as a remarkable prognostic marker to determine the risk of mortality in many cases other than the AP, reflecting the state of inflammation $[13,14]$. In a recent study, RDW was independently associated with AP mortality [10]. The present study showed that RDW at admission and in the first $24 \mathrm{~h}$ were good predictors of AP mortality with AUC > 0.801 , which was higher than in other works with a reported AUC of 0.74-0.82 [10, 16]. Furthermore, we found an independent relationship with RDW-to-TSC ratio and AP mortality with AUC of 0.88 . In our study, the RDW to TSC ratio and RDW were superior to prognostic scores in determining AP mortality. In a study also investigated the effect of RDW-platelet ratio on AP mortality with an AUC of 0.783 [17]. In contrast, our work showed that it was not an independent prognostic factor for mortality $(\mathrm{p}=$ 0.504 ).

In the present study, the diagnostic accuracy of RDW (AUC $>0.801$ ) was significantly higher than the other studied risk factors with $81.8 \%$ sensitivity, $87.2 \%$ specificity, $86.4 \%$ PPV and $82.8 \%$ NPV at cutoff $>16.6 \%$. This was comparable to the findings of Şenol et al [10], who reported RDW having AUC of 0.817 with $47.6 \%$ sensitivity, $96.3 \%$ specificity, $79.9 \%$ PPV and $87.6 \%$ NPV at cut off $>14.8$ in predicting fatal outcome in AP patients. In prior studies found that serum glucose level on admission was significantly higher among AP non-survivors. This was consistent with previous studies showing that serum glucose was considered as a satisfactory predictor of mortality in AP. Our findings revealed that at a cut off value $>151 \mathrm{mg} / \mathrm{dl}$ ); it had an AUC of 0.797 , 
$83.6 \%$ sensitivity, $70.7 \%$ specificity, $74.3 \% \mathrm{PPV}$ and $81.6 \%$ NPV in predicting AP-related in-hospital mortality.

In the past, RDW has been widely used in the differential diagnosis of anemia. In recent years, RDW has been associated with systemic inflammation because of high oxidative stress that contributes to reducing red blood cell (RBC) and RDW elevation and and increasing the release of large premature $\mathrm{RBCs}$ in the peripheral circulation and modifying $\mathrm{RBC}$ membrane glycoproteins and ion channels contributes to the change of RBC morphology [18, 19]. For this reason, RDW reflects systemic inflammation and thus, can be used to estimate the severity of the AP. Although TSC did not represent a good marker for AP mortality in our study, RDW-toTSC ratio has been shown to be a good indicator of AP mortality.

\section{Limitations}

There are several limitations for this study. First, our study is retrospective nature. Second, the sample size of this study is relatively small and the results are only from one center. Third, one of the most important limitations of our study is the lack of evaluation of comorbid diseases such as cardiovascular disease that may have an impact on mortality. Another limitation is that blood parameters before and during hospitalization of patients have not been studied. Further studies are needed with larger patient populations with multiple centers to more accurately assess RDW as a determinant of mortality.

\section{CONCLUSION}

In conclusion, $\mathrm{WBC}$, platelet, RDW, serum glucose and RDW-to-TSC ratio can predict AP related in-hospital mortality, where, RDW and RDW-to-TSC ratio have the higher prognostic accuracy. RDW $>$ 16.6 and RDW-to-TSC $>2.0$ were very-good predictors for AP mortality. Further prospective and multicenter studies are needed to more accurately evaluate the effect of high RDW as a marker for mortality in AP.

\section{Authorship declaration}

All authors listed meet the authorship criteria according to the latest guidelines of the International Committee of Medical Journal Editors, and all authors are in agreement with the manuscript.

\section{Conflict of interest}

The authors disclosed no conflict of interest during the preparation or publication of this manuscript.

\section{Financing}

The authors disclosed that they did not receive any grant during conduction or writing of this study.

\section{REFERENCES}

1. Kucukler FK, Simsek Y, Baglicaklioglu M, Adali G, Guler S. Acute pancreatitis and type 2 diabetes mellitus: who is guilty? Eur Res J 2015;1:74-7.

2. Papachristou GI, Muddana V, Yadav D, O'Connell M, Sanders MK, Slivka A, et al. Comparison of BISAP, Ranson's, APACHEII, and CTSI scores in predicting organ failure, complications, and mortality in acute pancreatitis. Am J Gastroenterol 2010;105:435-41.

3. Wang X, Cui Z, Zhang J, Li H, Zhang D, Miao B, et al. Early predictive factors of in-hospital mortality in patients with severe acute pancreatitis. Pancreas 2010;39:114-5.

4. Cho JH, Kim TN, Chung HH, Kim KH. Comparison of scoring systems in predicting the severity of acute pancreatitis. World $\mathbf{J}$ Gastroenterol 2015;21:2387-94.

5. Fisic E, Poropat G, Bilic-Zulle L, Licul V, Milic S, Stimac D, et al. The role of IL-6, 8, and 10, sTNFr, CRP, and pancreatic elastase in the prediction of systemic complications in patients with acute pancreatitis. Gastroenterol Res Pract 2013;2013: 282645.

6. Patel KV, Semba RD, Ferrucci L, Newman AB, Fried LP, Wallace RB, et al. Red cell distribution width and mortality in older adults: a meta-analysis. J Gerontol A Biol Sci Med Sci 2009;65:258-65.

7. Budak YU, Huysal K, Gecgel SK, Ari H, Melek M, Yavuz S, et al. Red cell distribution width, other hematological parameters and atherogenic index of plasma in patients with clopidogrel and aspirin resistance. Eur Res J 2016;2:200-5.

8. Agarwal S. Red cell distribution width, inflammatory markers and cardiorespiratory fitness: results from the National Health and Nutrition Examination Survey. Indian Heart J 2012;64:3807.

9. Seretis C, Seretis F, Lagoudianakis E, Gemenetzis G, Salemis NS. Is red cell distribution width a novel biomarker of breast cancer activity? Data from a pilot study. J Clin Med Res 2013;5:121-6.

10. Şenol K, Saylam B, Kocaay F, Tez M. Red cell distribution width as a predictor of mortality in acute pancreatitis. Am J Emerg Med 2013;31:687-9.

11. Wang D, Yang J, Zhang J, Li H, Zhang D, Miao B, et al. Red cell distribution width predicts deaths in patients with acute pancreatitis. J Res Med Sci 2015;20:42-4.

12. Banks P, Bollen T, Dervenis C, Gooszen HG, Johnson CD, 
Sarr MG, et al. Classification of acute pancreatitis-2012: revision of the Atlanta classification and definitions by international concensus. Gut 2013;62:102-11.

13. Makhoul BF, Khourieh A, Kaplan M, Bahouth F, Aronson D, Azzam ZS, et al. Relation between changes in red cell distribution width and clinical outcomes in acute decompensated heart failure. Int J Cardiol 2013;167:1412-6.

14. Hong N, Oh J, Kang S-M, Kim SY, Won H, Youn JC, et al. Red blood cell distribution width predicts early mortality in patients with acute dyspnea. Clin Chim Acta 2012;413:992-7.

15. Braun E, Domany E, Kenig Y, Mazor Y, Makhoul BF, Azzam $\mathrm{ZS}$, et al. Elevated red cell distribution width predicts poor outcome in young patients with community acquired pneumonia. Crit Care 2011;15:R194.

16. Li Y, Zhao Y, Feng L, Guo R. Comparison of the prognostic values of inflammation markers in patients with acute pancreatitis: a retrospective cohort study. BMJ open 2017; 7:13206.

17. Cetinkaya E, Şenol K, Saylam B, Tez M. Red cell distribution width to platelet ratio: new and promising prognostic marker in acute pancreatitis. World J Gastroenterol 2014;20:14450-54.

18. Song CS, Park DI, Yoon MY, Seok HS, Park JH, Kim HJ, et al. Association between red cell distribution width and disease activity in patients with inflammatory bowel disease. Dig Dis Sci 2012;57:1033-8.

19. Ku NS, Kim H-w, Oh HJ, Kim YC, Kim MH, Song JE, et al. Red blood cell distribution width is an independent predictor of mortality in patients with gram-negative bacteremia. Shock 2012;38:123-7. 